\title{
Minimum Energy Conformations of DNA Dimeric Subunits: Potential Energy Calculations for dGpdC, dApdA, dCpdC, dGpdG, and dTpdT
}

\author{
S. BROYDE, Bialogy Department, New York University, New York, \\ N.Y. 10003; R. M. WARTELL, Schools of Physics and Biology, Georgia \\ Institute of Technology, Atlanta, Georgia 30332; S. D. STELLMAN, \\ American Health Foundation, New York, New York 10019; and B. \\ HINGERTY, MRC Laboratory of Molecular Biology, Cambridge, CB2 \\ $2 Q H$, Great Britain
}

\begin{abstract}
Synopsis
Minimum energy conformations have been calculated for the deoxydinucleoside phosphates $\mathrm{dGpdC}, \mathrm{dApdA}, \mathrm{dCpdC}, \mathrm{dGpdG}$, and dTpdT. In these potential energy calculations the eight dihedral angles and the sugar pucker were flexible parameters. A substantial survey of conformation space was made in which all staggered combinations of the dihedral angles $\omega^{\prime}$, $\omega$, and $\psi$, in conjunction with $\mathrm{C}\left(2^{\prime}\right)$-endo and $\mathrm{C}\left(3^{\prime}\right)$-endo pucker, were used as starting conformers for the energy minimization. The most important conformations in the $\mathrm{C}\left(3^{\prime}\right)$ endo-puckering domain have $\psi=g^{+} ; \omega^{\prime}, \omega=g^{-} g^{-}$(A-form), $g^{+}, g^{+}$, and $g^{-}, t$. With C(2')endo-type pucker the most important conformations have $\psi=g^{+} ; \omega^{\prime}, \omega=g^{-}, g^{-}$(B-form) and $g^{+}, t$; and $\psi=t ; \omega^{\prime}, \omega=g^{-}, t$ (Watson-Crick form) and $t, g^{+}$(skewed). Stacked bases are a persistent feature of the low-energy conformations, the $g^{+}, t$ conformer being an exception. Freeing the sugar pucker allowed this conformation to become low energy, with $\mathrm{C}\left(3^{\prime}\right)$-exo pucker. It also caused other low-energy forms, such as the Watson-Crick conformation, to become more favorable. Conformational flexibility in the sugar pucker and in $\psi$, as well as the $\omega^{\prime}, \omega$ angle pair, is indicated for the dimeric subunits of DNA.
\end{abstract}

\section{INTRODUCTION}

Since the advent of the Watson-Crick model, ${ }^{1}$ the structure of DNA has been identified with the double helix. Nonetheless, as the molecular conformations comprising the helix are obtained with increasing confidence, it is becoming evident that DNA possesses considerable conformational variability. Fiber diffraction studies ${ }^{2,3}$ which revealed that the conformational details in the Watson-Crick model ${ }^{4}$ differ from those obtained in later refinements, also show that the A- and B-form fibers are themselves variable in helix geometry depending on the base sequence. ${ }^{3}$ Although detailed information on the conformations in the ordered DNA helices is now available, little is known about the conformations of the coil form existing in solution. The conformations existing in loop regions of DNAs are also unknown, although such information is emerging for the RNAs from the crystal structure of the yeast phenylalanine tRNAs. ${ }^{5-8}$ In chromatin DNA is believed to be highly folded, ${ }^{9}$ necessitating alternate conformations 
which produce turns between the double-helical segments; these conformations are also not known, although interesting models for a "kinky helix," ${ }^{10,11}$ as well as for a smoothly bent helix, have been proposed (J. Sussman and E. Trifinov, and W. K. Olson, personal communications).

While $\mathrm{x}$-ray diffraction analyses of fibers and crystals of nucleic acids provide unequivocal experimental information on the most important conformations in these states, classical potential energy methods have proven fruitful in delineating the various favorable conformational regions ${ }^{12-15}$ relevant to both the dynamic situation occurring in solution and to crystal structures. When combined with energy minimization, these methods have permitted calculation of low-energy conformational angles, ${ }^{16-22}$ and in some cases to predict entire crystalline structures. ${ }^{16}$ In our earlier calculations on the ribodinucleoside phosphates ${ }^{16-18}$ and on $\mathrm{dGpdC},{ }^{20}$ all torsional angles were flexible parameters. However, the sugar pucker was held fixed in the $\mathrm{C}\left(2^{\prime}\right)$-endo or $\mathrm{C}\left(3^{\prime}\right)$-endo conformations (except in the work on the smaller $2^{\prime}-0$-methylcytidine ${ }^{19}$ ). In the present work on deoxy dimers the sugar pucker is also flexible.

We report here calculated low-energy conformations for the deoxydinucleoside phosphates dGpdC, dApdA, dTpdT, dCpdC, and dGpdG. A substantial survey of conformation space was made in which all staggered combinations of the dihedral angles $\omega^{\prime}, \omega$, and $\psi$ were used as starting conformers for the minimization, in conjunction with both $\mathrm{C}\left(2^{\prime}\right)$-endo and $\mathrm{C}\left(3^{\prime}\right)$-endo pucker. In addition to the A- and B-forms for which helical parameters are presented elsewhere, ${ }^{23}$ a number of other low-energy conformers are obtained which may occur in coils, kinks, or in drug intercalated DNA.

Figure 1 shows the structure, numbering scheme, and angle conventions for $\mathrm{dGpdC}$, and for adenine and thymine, as well as dihedral angle definitions.

Coordinates of the molecules were generated via the linked atom algorithm of Scott and Scheraga, ${ }^{24}$ using the bond distances and bond angles given by Arnott et al. ${ }^{25}$ The bond lengths were not permitted to vary, but the five deoxyribose bond angles were variable (see below). This method permits the direct calculation of Cartesian coordinates, needed in the later energy calculations, from the dihedral angles and the sugar puckering, which are variable.

The energy, $E$, of a molecule was calculated by the equation

$$
E=E_{\mathrm{nb}}+E_{\mathrm{el}}+E_{\mathrm{tor}}+E_{\mathrm{st}}
$$

where $E_{\mathrm{nb}}, E_{\mathrm{el}}, E_{\mathrm{tor}}$, and $E_{\mathrm{st}}$ are respectively the nonbonded, electrostatic, torsional, and deoxyribose bond angle strain energies, in $\mathrm{kcal} / \mathrm{mol}$. These quantities are computed as follows:

$$
\begin{gathered}
E_{\mathrm{nb}}=\sum \sum_{i<j}\left(a_{i j} r_{i j}^{-6}+b_{i j} r_{i j}^{-12}\right) \\
E_{\mathrm{el}}=\sum \sum_{i<j} 332 q_{i} q_{j} r_{i j}^{-1} \epsilon^{-1}
\end{gathered}
$$




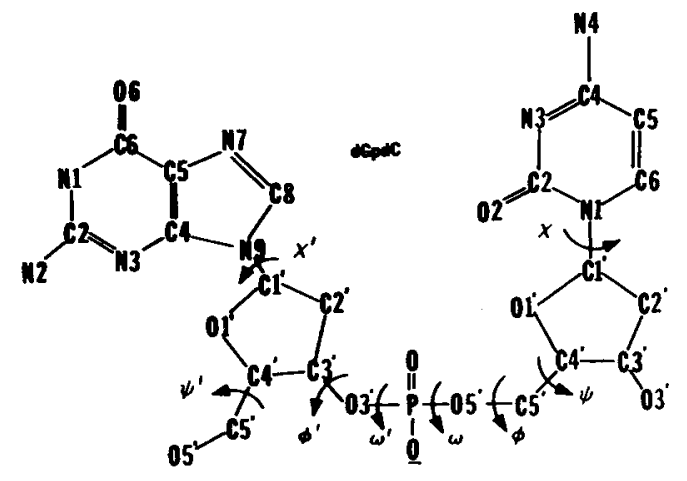

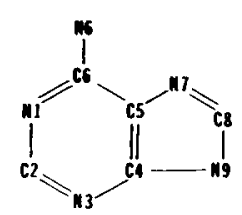

adenine<smiles>C[As]1=CCNC(=O)N1</smiles>

thymine

Fig. 1. Structure, numbering scheme, and conformational angle designations for dGpdC. Structure and numbering scheme for adenine and thymine. The dihedral angles $\mathrm{A}-\mathrm{B}-\mathrm{C}-\mathrm{D}$ are defined as follows: $\chi^{\prime}, \chi: \quad \mathrm{O} 1^{\prime}-\mathrm{C} 1^{\prime}-\mathrm{N} 9-\mathrm{C} 8(\mathrm{Pur}), \mathrm{O} 1^{\prime}-\mathrm{C} 1^{\prime}-\mathrm{N} 1-\mathrm{C} 6(\mathrm{Pyr}) ; \psi^{\prime}$ (the exocyclic $\left.\mathrm{C}^{\prime}-\mathrm{C} 5^{\prime}\right), \psi: \mathrm{C} 3^{\prime}-\mathrm{C}^{\prime}-\mathrm{C} 5^{\prime}-\mathrm{O}^{\prime} ; \phi^{\prime}: \mathrm{P}-\mathrm{O}^{\prime}-\mathrm{C} 3^{\prime}-\mathrm{C} 4^{\prime} ; \phi: \mathrm{C}^{\prime}-\mathrm{C}^{\prime}-\mathrm{O} 5^{\prime}-\mathrm{P}$; $\omega^{\prime}: \quad 5^{\prime}-\mathrm{P}^{\prime}-\mathrm{O}^{\prime}-\mathrm{C}^{\prime} ; \omega: \mathrm{C}^{\prime}-\mathrm{O}^{\prime}-\mathrm{P}-\mathrm{O}^{\prime}$. The angle $\mathrm{A}-\mathrm{B}-\mathrm{C}-\mathrm{D}$ is measured by a clockwise rotation of $\mathrm{D}$ with respect to $\mathrm{A}$, looking down the $\mathrm{B}-\mathrm{C}$ bond.

$$
\begin{gathered}
E_{\mathrm{tor}}=\sum_{k=1}^{8} \frac{V_{0, k}}{2}\left(1+\cos 3 \theta_{k}\right) \\
E_{\mathrm{st}}=\sum_{l=1}^{5} K_{\tau l}\left(\tau_{l}-\tau_{0, l}\right)^{2}
\end{gathered}
$$

where $r_{i j}$ is the distance in angstroms between atoms $i$ and $j, q_{i}$ is the partial charge assigned to atom $i, \epsilon$ is the dielectric constant, $V_{0, k}$ is the barrier to internal rotation for the $k$ th dihedral angle and $\theta_{k}$ is the value of that angle, $K_{\tau_{l}}$ is a force constant, $\tau_{l}$ is the (strained) deoxyribose bond angle, and $\tau_{0, l}$ is the value that angle adopts at equilibrium. Also, $k$ denotes the eight dihedral angles and $l$, the five deoxyribose bond angles. Values for the parameters $a_{i j}, b_{i j}, q_{i}$, and $V_{0, k}$ were taken from Refs. 13,14 , and 26 and a dielectric constant of 4 was employed, except where otherwise indicated.

The energy of deoxyribose was calculated previously by Dr. T. Sato, some of whose results have been reported by Sasisekharan. ${ }^{27}$ In his work the energy was minimized as a function of the pseudorotation parameter, $\mathbf{P}$, the puckering amplitude, $\theta_{m}$ (notation of Altona and Sundaralingam ${ }^{28}$ ), and the bond angles $\mathrm{O} 1^{\prime}-\mathrm{C} 1^{\prime}-\mathrm{C} 2^{\prime}\left(\alpha_{1}\right)$ and $\mathrm{O}^{\prime}-\mathrm{C} 4^{\prime}-\mathrm{C} 3^{\prime}\left(\alpha_{2}\right)$. These completely define the deoxyribose coordinates. For these calculations, $\tau_{0}$ was taken to be $113.5^{\circ} \mathrm{C}$ for $\mathrm{C}-\mathrm{C}-\mathrm{O}$ and $109.5^{\circ} \mathrm{C}$ for $\mathrm{C}-\mathrm{C}-\mathrm{C} . K_{\tau}$ values employed were, in $\mathrm{kcal} / \mathrm{mol} \mathrm{rad}^{2}, 66.5^{\circ}$ for $\mathrm{C}-\mathrm{O}-\mathrm{C}, 59.5^{\circ}$ for 
$\mathrm{C}-\mathrm{C}-\mathrm{O}$, and $54.0^{\circ}$ for $\mathrm{C}-\mathrm{C}-\mathrm{C}$. These are $70 \%$ of the values obtained experimentally, ${ }^{29}$ and were devaluated by Sato in order to obtain a better fit between observed and calculated conformations. Results of Sato's calculations, which have not been previously published, are presented in Fig. 2. Two minima were found for deoxyribose, one with $\mathrm{C}\left(2^{\prime}\right)$-endo$\mathrm{C}\left(3^{\prime}\right)$-exo pucker $\left(E_{n}=4.57 \mathrm{kcal} / \mathrm{mol}\right)$, and a second of slightly higher energy $\left(E_{n}=4.37 \mathrm{kcal} / \mathrm{mol}\right)$ with $\mathrm{C}\left(3^{\prime}\right)$-endo-C $\left(2^{\prime}\right)$-exo pucker. Quantum mechanical calculations have also obtained these two almost equal minima for deoxyribose. ${ }^{30}$ These energies and the other variables in Fig. 2 were incorporated in the energy calculations of the present work, and by linear interpolation permitted a continuous variation in deoxyribose energy as a function of puckering.

Energies in Eq. (1) were calculated for the interaction of every atom with every other atom, excluding those interactions where the interatomic distance is invariant with a change in conformation. The eight dihedral angles and the sugar pucker were flexible, and served as the variable parameters for the energy minimization, which was carried out by a modified version of the Powell algorithm. ${ }^{31}$

The minimizations were carried to an accuracy of $1^{\circ}$ in each parameter at the minimum, with no angle permitted to vary by more than $100^{\circ}$ at any step. In practice, the variation incurred per step was usually only a few degrees. Very rarely the routine would "jump" from one staggered conformational region to another, which encompasses about $100^{\circ}$.

There were two stages to the calculations. In the first stage, the sugar pucker was fixed at $\mathbf{P}=18^{\circ}\left[\mathrm{C}\left(3^{\prime}\right)\right.$-endo envelope $]$ or $\mathbf{P}=162^{\circ}\left[\mathrm{C}\left(2^{\prime}\right)\right.$-endo

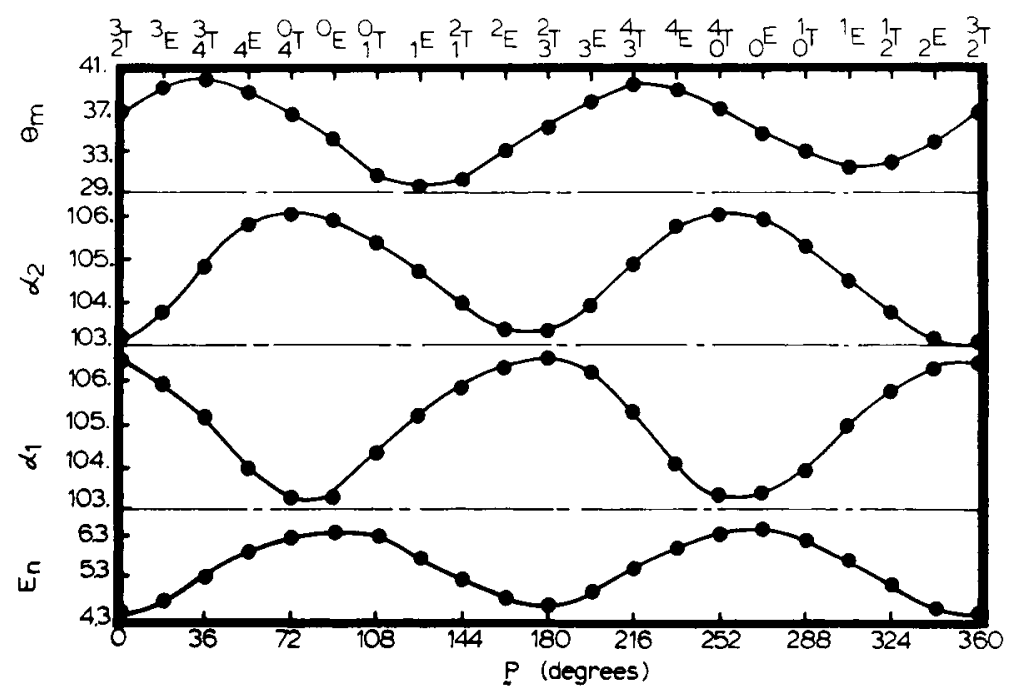

Fig. 2. Energy, En, of deoxyribose (kcal/mol); $\alpha_{1}$, the bond angle $\mathrm{O} 1^{\prime}-\mathrm{C} 1^{\prime}-\mathrm{C} 2^{\prime}(\mathrm{deg}) ; \alpha_{2}$, the bond angle $\mathrm{O1}^{\prime}-\mathrm{C} 4^{\prime}-\mathrm{C} 3^{\prime}(\mathrm{deg})$; and $\theta_{m}$, the puckering amplitude (deg) as a function of $P$, the pseudorotation parameter. $T=$ twist, $E=$ envelope conformation. Upper number designates deoxyribose atom that is endo; lower number is exo atom. 
envelope], together with the corresponding values of $\theta_{m}, \alpha_{1}$, and $\alpha_{2}$ (Fig. 2). Then calculations were made for the following combinations of starting conformations: $\chi^{\prime}, \chi=15^{\circ}\left[\mathrm{C}\left(3^{\prime}\right)\right.$-endo $]$ or $55^{\circ}\left[\mathrm{C}\left(2^{\prime}\right)\right.$-endo $]$ (anti); $\phi^{\prime}=$ $200^{\circ} ; \psi^{\prime}, \psi=60^{\circ}, 180^{\circ}, 300^{\circ} ; \omega^{\prime}, \omega=60^{\circ}, 180^{\circ}, 290^{\circ} ; \phi=180^{\circ}$. For dGpdG also $\chi^{\prime}, \chi=220^{\circ}$ (syn). This represents a study of all staggered combinations of $\psi^{\prime}$ (the exocyclic C4'-C $5^{\prime}$ bond), $\psi, \omega^{\prime}$, and $\omega$. There were thus 81 trials for each of the two sugar puckers, for each molecule (and twice as many for $\mathrm{dGpdG}$ ). In the next stage, the sugar pucker was freed. All conformations that were within $\sim 5 \mathrm{kcal} / \mathrm{mol}$ of the global minimum for each puckering region were used as starting parameters in a subsequent minimization in which the sugar pucker was now also variable. The minimization method never leaves one entirely satisfied that all low-energy local minima have been found, because the minimum arrived at depends on the starting position. However, a large number of trials were made in the present work. In addition, we find that important conformational regions have low-energy domains that are both deep and wide, and are reached from a variety of similar starting positions.

Energy contour maps in the $\omega^{\prime}, \omega$ plane were made with the other conformational angles and the sugar pucker fixed at values in the vicinity of the relevant local minima. The energy was computed for the two angles at $18^{\circ}$ intervals, giving a total of 400 points. Plots were made with CALCOMP's General Purpose Contouring Program. Calculations were made on the CDC Cyber 70-72/28 at the Georgia Institute of Technology.

\section{RESULTS}

\section{dGpdC}

Table I presents low-energy conformations of dGpdC. Overall results with the sugar pucker fixed at either ${ }^{3} E$ or ${ }^{2} E$, published previously, ${ }^{20}$ were similar. However, freeing the sugar pucker did have an important effect, namely, that all the low-energy conformations moved closer to one another in energy. The energy reductions came about by a modification of the sugar pucker from the envelope to the twist form. The A-form of DNA remained the global minimum and its sugar pucker remained ${ }^{3} E$. The B-like form fell to a $\Delta E_{1}$ (relative to the global minimum) of $0.2 \mathrm{kcal} / \mathrm{mol}$. Its energy with sugar pucker fixed at ${ }^{2} E$ had been $0.4 \mathrm{kcal} / \mathrm{mol}$. The conformation with backbone dihedral angles like the Watson-Crick model ${ }^{4}$ had $\omega^{\prime}, \omega=$ $g^{-}, t$ and $\psi=$ trans. (The Watson-Crick model, however, had $\mathrm{C}\left(3^{\prime}\right)$-endo pucker.) Its energy decreased more significantly, from $\Delta E_{1}=2.3 \mathrm{kcal} / \mathrm{mol}$ to $0.8 \mathrm{kcal} / \mathrm{mol}$. Zhurkin et al. ${ }^{32}$ have also found the Watson-Crick helix a favorable conformation in their calculations on double-stranded structures. 
TABLE I

Selected Minimum Energy Conformations of dGpdCa

\begin{tabular}{|c|c|c|c|c|c|c|c|c|c|c|c|}
\hline & & & & & & & & & & & Description \\
\hline$\chi^{\prime}$ & $\psi^{\prime}$ & $\varphi^{\prime}$ & $\omega^{\prime}$ & $\omega$ & $\varphi$ & $\psi$ & $x$ & $\mathbf{P}$ & $\Delta E_{1}$ & $\Delta E_{2}$ & $\begin{array}{l}\sim \omega^{\prime}, \omega ; \psi \\
\text { Pucker }\end{array}$ \\
\hline \multicolumn{12}{|c|}{$\mathrm{C}\left(3^{\prime}\right)$-endo Region } \\
\hline 9 & 62 & 197 & 302 & 283 & 187 & 49 & 32 & 17 & 0 & & $\begin{array}{l}g^{-}, g^{-} ; g^{+} ;{ }^{3} E \\
\text { (A) }\end{array}$ \\
\hline 16 & 56 & 176 & 21 & 81 & 192 & 63 & 11 & 11 & 1.3 & & $g^{+}, g^{+} ; g^{+} ;{ }_{2}^{3} T$ \\
\hline 18 & 176 & 193 & 294 & 158 & 190 & 162 & 8 & -3 & 2.4 & & $g^{-}, t ; t ;{ }_{2}^{3} T$ \\
\hline \multicolumn{12}{|c|}{$\mathrm{C}\left(2^{\prime}\right)$-endo Region } \\
\hline 65 & 59 & 172 & 257 & 302 & 191 & 46 & 65 & 169 & 0.2 & 0 & $\begin{array}{l}g^{-}, g^{-} ; g^{+} ;{ }_{2}^{3} T \\
\text { (B) }\end{array}$ \\
\hline 60 & 179 & 171 & 259 & 164 & 173 & 173 & 39 & 184 & 0.8 & 0.6 & $g^{-}, t ; t ;{ }_{3} E$ \\
\hline 55 & 178 & 182 & 232 & 46 & 152 & 315 & 73 & 187 & 2.7 & 2.5 & $t, g^{+*} ; g^{-} ;{ }_{3} E$ \\
\hline
\end{tabular}

a $\Delta E_{1}$ is the energy difference in $\mathrm{kcal} / \mathrm{mol}$ between the local minimum and the global minimum. $\Delta E_{2}$ is the energy difference between the local minimum and the $\mathrm{C}\left(2^{\prime}\right)$-endo lowestenergy conformation. Dihedral angles and $\mathbf{P}$ are in degrees. Sugar-pucker designations are taken from Fig. 2. A conformation is described as twist if $\mathbf{P}$ is more than $5^{\circ}$ from the pure envelope conformation. The ${ }^{*}$ denotes skewed.

\section{dApdA}

Table II shows lowest-energy conformations of dApdA. Others, up to about $5 \mathrm{kcal} / \mathrm{mol}$, are summarized in Table VI. In contrast with dGpdC, many more low-energy conformations were obtained. In the $\mathrm{C}\left(3^{\prime}\right)$-endopuckering domain the $g^{+}$region of $\psi$ was most important. Three $\omega^{\prime}, \omega$

TABLE II

Selected Minimum Energy Conformations of dApdA ${ }^{a}$

\begin{tabular}{|c|c|c|c|c|c|c|c|c|c|c|c|}
\hline & & & & & & & & & & & Description \\
\hline$\chi^{\prime}$ & $\psi^{\prime}$ & $\varphi^{\prime}$ & $\omega^{\prime}$ & $\omega$ & $\varphi$ & $\psi$ & $\underline{x}$ & $\mathbf{P}$ & $\Delta E_{1}$ & $\Delta E_{2}$ & $\sim \omega^{\prime}, \omega ; \psi ;$ Pucker \\
\hline \multicolumn{12}{|c|}{$\mathrm{C}\left(3^{\prime}\right)$-endo Region } \\
\hline-12 & 180 & 186 & 305 & 201 & 252 & 72 & 36 & 16 & 0 & & $g^{-}, t ; g^{+, 3} E$ \\
\hline 5 & 61 & 208 & 312 & 280 & 183 & 47 & 21 & 7 & 0.2 & & $\begin{array}{l}g^{-} g^{-}, g^{+} ;{ }_{2}^{3} T \\
\text { (A) }\end{array}$ \\
\hline 48 & 60 & 187 & 41 & 76 & 196 & 84 & 30 & 10 & 0.5 & & $g^{+}, g^{+} ; g^{+} ;{ }_{2}^{3} T$ \\
\hline 55 & 64 & 175 & 50 & 233 & 158 & 312 & 39 & 0 & 1.6 & & $g^{+}, t^{*}, g^{-} ;{ }_{2}^{3} T$ \\
\hline 25 & 173 & 283 & 203 & 86 & 263 & 163 & 32 & -3 & 1.7 & & $t g^{+} ; t ;{ }_{2}^{3} T$ \\
\hline \multicolumn{12}{|c|}{$\mathrm{C}\left(2^{\prime}\right)$-endo Region } \\
\hline 79 & 61 & 168 & 261 & 303 & 185 & 52 & 83 & 177 & 2.0 & 0 & $\begin{array}{l}g^{-}, g^{-} ; g^{+} ;{ }_{3}^{2} T \\
\text { (B) }\end{array}$ \\
\hline 16 & 60 & 183 & 234 & 85 & 185 & 190 & -23 & 191 & 2.3 & 0.4 & $t, g^{+*} ; t ;{ }_{3}^{2} T$ \\
\hline-20 & 179 & 194 & 57 & 167 & 182 & 51 & 13 & 204 & 2.7 & 0.7 & $g^{+}, t ; g^{+} ;{ }_{3} E$ \\
\hline 57 & 56 & 174 & 267 & 148 & 180 & 181 & 44 & 175 & 2.8 & 0.8 & $g^{-}, t ; t ;{ }_{3}^{2} T$ \\
\hline 149 & 66 & 195 & 272 & 306 & 183 & 314 & 6 & 197 & 3.3 & 1.3 & $g^{-}, g^{-} ; g^{-} ;{ }_{3} E$ \\
\hline 123 & 59 & 201 & 297 & 182 & 177 & 68 & 17 & 155 & 4.3 & 2.3 & $g^{-}, t ; g^{+} ;{ }_{1}^{2} T$ \\
\hline
\end{tabular}

a See footnote to Table I. 
conformations were found within $0.5 \mathrm{kcal} / \mathrm{mol}: g^{-}, t\left(\Delta E_{1}=0\right) ; g^{-}, g^{-}$(the $\mathrm{A}$-form, $\left.\Delta E_{1}=0.2\right)$; and $g^{+}, g^{+}\left(\Delta E_{1}=0.5\right)$. These are the same general regions obtained for $\mathrm{ApA}$, although the angles are more classically staggered in the deoxy molecule. With $\psi=$ trans, the $t, g^{+}$region of $\omega^{\prime}, \omega$ is low energy, and with $\psi=g^{-}, \omega^{\prime}, \omega=g^{+}, t$ (skewed) is favorable.

In the $\mathrm{C}\left(2^{\prime}\right)$-endo domain, the B-form $\left(\omega^{\prime}, \omega=g^{-}, g^{-} ; \psi=g^{+}\right)$is the lowest-energy conformer. Another important form with $\psi=g^{+}$, and $\omega^{\prime}, \omega$ $=g^{+}, t$ is $0.7 \mathrm{kcal} / \mathrm{mol}$ higher in energy. With $\psi=$ trans, there are also two low-energy $\omega^{\prime}, \omega$ regions: $t, g^{+}$(skewed) and $g^{-}, t$ (the Watson-Crick conformation). With $\psi=g^{-}$, the $g^{-}, g^{-}$region of $\omega^{\prime}, \omega$ is low energy. In the $\mathrm{C}\left(2^{\prime}\right)$-endo-puckering domain, $\mathbf{P}$ covers a much wider range than for $\mathrm{C}\left(3^{\prime}\right)$-endo. In fact, this range is broad enough $\left(\sim 50^{\circ}\right)$ to include several $\mathrm{C}\left(3^{\prime}\right)$-exo conformers.

The bases are stacked and nearly parallel in all dApdA conformations except the $\omega^{\prime}, \omega=g^{+}, t, \psi=g^{+}, \mathrm{C}\left(3^{\prime}\right)$-exo conformation. This exemplifies the importance of stacking as a major force in determining low-energy conformations. Figure 3 depicts the most important dApdA conformers; these are representative of the preferred conformations obtained for the other molecules as well.

\section{dCpdC}

Table III presents lowest-energy conformations of dCpdC. We observe that the same kinds of conformations are important as for dApdA, particularly in the $\mathrm{C}\left(2^{\prime}\right)$-endo region. It is interesting to note that two local minima were obtained for both the A- and B-forms in $\mathrm{dCpdC}$. The $g^{+}, g^{+}$ conformation of $\omega^{\prime}, \omega$ with ${ }^{3} E$ pucker and $\psi=g^{+}$is the global minimum. However, the $\omega^{\prime}, \omega=g^{-}, t$ region with ${ }^{3} E$ pucker is not among the lowest energies for $\mathrm{dCpdC}$, as it is for $\mathrm{dApdA}$ and for $\mathrm{CpC}$.

The $g^{+}, t$ region of $\omega^{\prime}, \omega$, with $\mathrm{C}\left(3^{\prime}\right)$-exo sugar, is the lowest-energy conformation in its puckering domain. As in dApdA, this conformation is unstacked. The calculated $\mathrm{B}$-form of $\mathrm{dCpdC}$ also has relatively little base overlap, although the bases are nearly parallel. ${ }^{23}$ In this connection, it is of interest that little stacking is observed for $\mathrm{dCpdC}$ in solution, ${ }^{33}$ which may therefore be comprised primarily of these conformers.

\section{dGpdG}

Table IV presents low-energy conformations of dGpdG. This molecule exhibits important differences from the other molecules. First among these is the preference of $\mathrm{dGpdG}$ for the syn conformation of the bases, just as has been calculated for $\mathrm{GpG}^{17}$ and for shorter ribo fragments of guanosine ${ }^{34,35}$ This preference results in a surprising conformation as the global minimum of $\mathrm{dGpdG}$ : the $\omega^{\prime}, \omega$ pair are near $90^{\circ}, 250^{\circ}$ (here referred to as $g^{+}, t^{*}$, where the asterisk indicates that $\omega$ is skewed. The $g^{+}, t^{*}$ designation applies to the $\omega$ region of $\left.\sim 230^{\circ}-250^{\circ}\right) . \psi$ is $g^{-}$and the pucker 
(a)

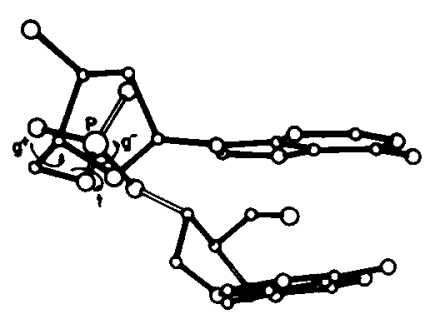

(c)

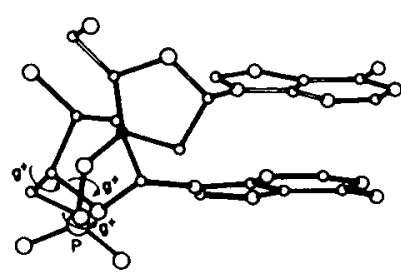

(e)

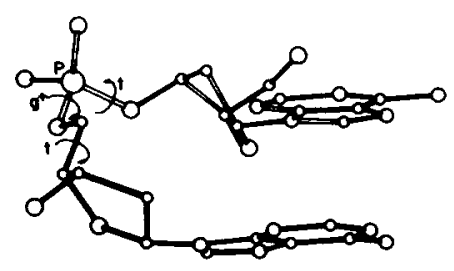

(g)

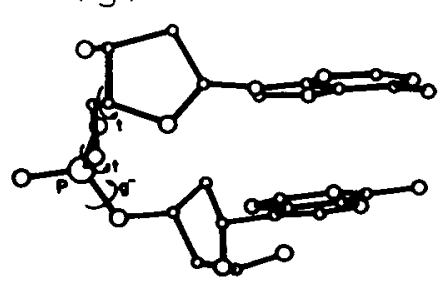

(b)

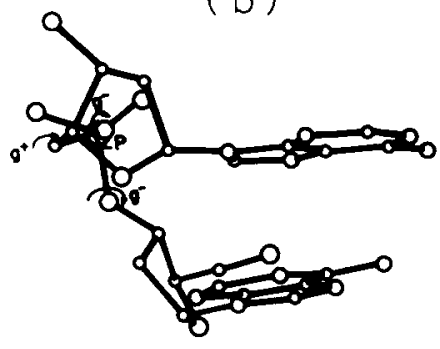

(d)

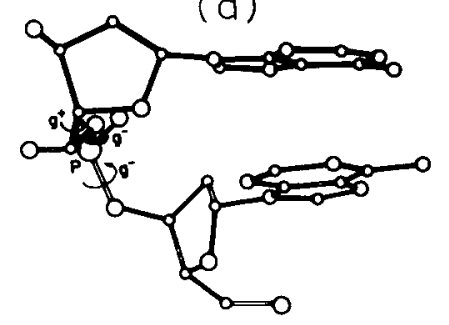

( $f)$
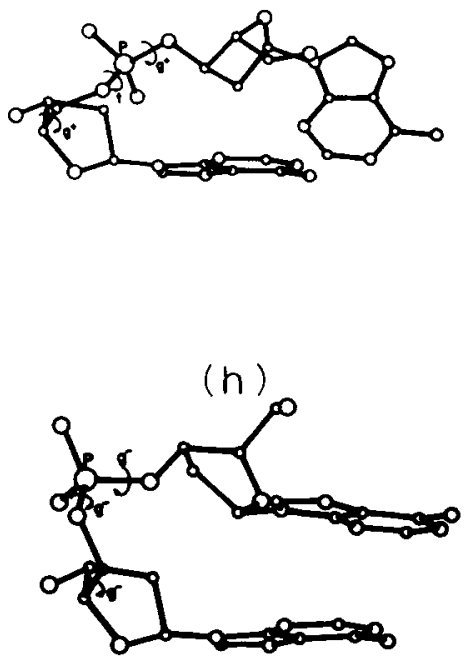

Fig. 3. Low-energy conformers of dApdA. The three lowest-energy $\mathrm{C}\left(3^{\prime}\right)$-endo $(\mathrm{a}, \mathrm{b}, \mathrm{c})$ and the five lowest-energy $\mathrm{C}\left(2^{\prime}\right)$-endo $(\mathrm{d}, \mathrm{e}, \mathrm{f}, \mathrm{g}, \mathrm{h})$ conformations from Table II are shown.

is ${ }^{3} E$. Figure 4(a) shows that this conformer has considerable stacking of the six-membered rings, which would not occur if the bases were anti. However, our preliminary calculations show it does not have low energy 
TABLE III

Selected Minimum Energy Conformations of $\mathrm{dCpdC}^{a}$

\begin{tabular}{|c|c|c|c|c|c|c|c|c|c|c|c|}
\hline$\chi^{\prime}$ & $\psi^{\prime}$ & $\varphi^{\prime}$ & $\omega^{\prime}$ & $\omega$ & $\varphi$ & $\psi$ & $\chi$ & $\mathbf{P}$ & $\Delta E_{1}$ & $\Delta E_{2}$ & $\begin{array}{c}\text { Description } \\
\sim \omega^{\prime}, \omega ; \psi ; \\
\text { Pucker }\end{array}$ \\
\hline \multicolumn{12}{|c|}{$\mathrm{C}\left(3^{\prime}\right)$-endo Region } \\
\hline 46 & 62 & 186 & 42 & 77 & 198 & 84 & 25 & 20 & 0 & & $\mathrm{~g}^{+}, \mathrm{g}^{+} ; \mathrm{g}^{+} ;{ }^{3} E$ \\
\hline 5 & 59 & 207 & 324 & 273 & 182 & 50 & 22 & 14 & 2.2 & & $\begin{array}{l}g^{-}, g^{-} ; g^{+} ;{ }^{3} E \\
\text { (A) }\end{array}$ \\
\hline 42 & 179 & 178 & 43 & 239 & 165 & 305 & 38 & 7 & 2.3 & & $g^{+}, t^{*} ; g^{-} ;{ }_{2}^{3} T$ \\
\hline 41 & 62 & 195 & 307 & 281 & 181 & 54 & 37 & 20 & 3.5 & & $\begin{array}{l}g^{-}, g^{-} ; g^{+} ;{ }^{3} E \\
\text { (A) }\end{array}$ \\
\hline \multicolumn{12}{|c|}{$\mathrm{C}\left(2^{\prime}\right)$-endo Region } \\
\hline 15 & 177 & 226 & 50 & 170 & 166 & 51 & 12 & 200 & 5.0 & 0 & $g^{+}, t ; g^{+} ;{ }_{3} E$ \\
\hline 62 & 53 & 173 & 270 & 142 & 196 & 183 & 50 & 168 & 7.2 & 2.2 & $g^{-}, t ; t ;{ }_{3}^{2} T$ \\
\hline 66 & 58 & 173 & 255 & 299 & 184 & 51 & 66 & 164 & 7.3 & 2.3 & $\begin{array}{l}g^{-}, g^{-} ; g^{+} ;{ }^{2} E \\
\text { (B) }\end{array}$ \\
\hline 65 & 61 & 183 & 273 & 306 & 164 & 54 & 72 & 142 & 7.8 & 2.8 & $\begin{array}{l}g^{-}, g^{-} ; g^{+} ;{ }_{1}^{2} T \\
\text { (B) }\end{array}$ \\
\hline 13 & 55 & 186 & 234 & 72 & 195 & 167 & 3 & 197 & 7.8 & 2.8 & $t, g^{+*} ; t ;{ }_{3} E$ \\
\hline 138 & 59 & 201 & 287 & 194 & 193 & 57 & 25 & 154 & 8.2 & 3.2 & $g^{-}, t ; g^{+} ;{ }_{1}^{2} T$ \\
\hline
\end{tabular}

a See footnote to Table I.

in larger structures because the phosphates are crowded. The A- and Bform helices still appear as local minima, but with relatively high energy, $\Delta E_{1}=6.7$ and $6.8 \mathrm{kcal} / \mathrm{mol}$, respectively. With $\psi=g^{+}$and $\mathrm{C}\left(3^{\prime}\right)$-endo pucker, the low-energy $\omega^{\prime}, \omega$ regions of $\mathrm{dGpdG}$ are the same as those obtained for $\mathrm{GpG}^{17}$ and for the other deoxy molecules: $g^{-}, t ; g^{+}, g^{+}$; and $g^{-}$, $g^{-}$. However, dGpdG apparently has a greater preference for the trans rotation of $\omega$. Many of the listed minima have $\omega^{\prime}, \omega=g^{-}, t$; with $\psi$ trans this is the lowest-energy conformation in the $\mathrm{C}\left(2^{\prime}\right)$-endo puckering region. Figure 4(b) shows dGpdG in this conformation. Compared to the other molecules, $\mathrm{dGpdG}$ also seems to have a greater propensity towards regions of $\psi$ different from $g^{+}$. The lowest-energy conformations with $\mathrm{C}\left(3^{\prime}\right)$-endo and $\mathrm{C}\left(2^{\prime}\right)$-endo pucker have $\psi=g^{-}$and $t$, respectively.

\section{dTpdT}

The most-favored minimum energy conformations of dTpdT are presented in Table V. In the $\mathrm{C}\left(3^{\prime}\right)$-endo domain with $\psi=g^{+}$, the A-form is the global minimum and the $g^{+}, g^{+}$region of $\omega^{\prime}, \omega$ is also low energy. A second, somewhat different A-form minimum occurred at $0.1 \mathrm{kcal} / \mathrm{mol}$, as was also observed with $\mathrm{dCpdC}$. When $\psi$ is $t$, the $\omega^{\prime}, \omega=g^{-}, t$ region is low energy, and when $\psi$ is $g^{-}$the $g^{+}, t^{*}$ (skewed) region of $\omega^{\prime}, \omega$ is low energy. For $\mathrm{C}\left(2^{\prime}\right)$-endo-type pucker, the $g^{-}, t$ domain of $\omega^{\prime}, \omega$ with $\psi=t$ is the lowest-energy conformation. The other low-energy regions have $\psi=g^{+}$and $\omega^{\prime}, \omega=g^{+}, t$; or $g^{-}, t$ or $g^{-}, g^{-}$(the B-form). The B-form is more than 5 
TABLE IV

Selected Minimum Energy Conformations of $\mathrm{dGpdG}^{\mathrm{a}}$

\begin{tabular}{|c|c|c|c|c|c|c|c|c|c|c|c|}
\hline \multirow[b]{2}{*}{$\underline{x}^{\prime}$} & \multirow[b]{2}{*}{$\psi$} & \multirow[b]{2}{*}{$\varphi^{\prime}$} & \multirow[b]{2}{*}{$\omega^{\prime}$} & \multirow[b]{2}{*}{$\omega$} & \multirow[b]{2}{*}{$\varphi$} & \multirow[b]{2}{*}{$\psi$} & \multirow[b]{2}{*}{$x$} & \multirow[b]{2}{*}{$\mathbf{P}$} & \multirow[b]{2}{*}{$\Delta E_{1}$} & \multirow[b]{2}{*}{$\Delta E_{2}$} & \multirow{2}{*}{$\begin{array}{c}\text { Description } \\
\text { Bases; } \sim \omega^{\prime}, \omega ; \psi ; \\
\text { Pucker }\end{array}$} \\
\hline & & & & & & & & & & & \\
\hline \multicolumn{12}{|c|}{$\mathrm{C}\left(3^{\prime}\right)$-endo Region } \\
\hline 218 & 177 & 185 & 91 & 249 & 145 & 294 & 226 & 20 & 0 & & $S-S ; g^{+}, t^{*} ; g^{-} ;{ }^{3} E$ \\
\hline 227 & 181 & 198 & 330 & 151 & 201 & 51 & 175 & 22 & 1.5 & & $S-S ; g^{-}, t ; g^{+} ;{ }^{3} E$ \\
\hline 26 & 180 & 178 & 294 & 147 & 180 & 188 & 187 & 12 & 2.7 & & $A-S ; g^{-}, t ; t ;{ }_{2}^{3} T$ \\
\hline 220 & 183 & 164 & 27 & 100 & 193 & 63 & 175 & 17 & 3.6 & & $S-S ; g^{+}, g^{+*} ; g^{+} ;{ }^{3} E$ \\
\hline 94 & 181 & 197 & 291 & 165 & 240 & 47 & 1 & 28 & 5.1 & & $A-A ; g^{-}, t ; g^{+} ;{ }^{3} E$ \\
\hline 6 & 180 & 207 & 311 & 281 & 183 & 47 & 24 & 7 & 6.7 & & $\begin{array}{l}A-A ; g^{-}, g^{-} ; g^{+} ;{ }_{2}^{3} T \\
\text { (A) }\end{array}$ \\
\hline \multicolumn{12}{|c|}{$\mathrm{C}\left(2^{\prime}\right)$-endo Region } \\
\hline 243 & 178 & 178 & 274 & 138 & 195 & 182 & 242 & 171 & 2.0 & 0 & $S-S ; g^{-}, t ; t ;{ }_{3}^{2} T$ \\
\hline 244 & 299 & 184 & 41 & 270 & 162 & 313 & 214 & 170 & 2.9 & 0.9 & $S-S ; g^{+}, g^{-} ; g^{-} ;{ }_{3}^{2} T$ \\
\hline 241 & 290 & 207 & 48 & 182 & 189 & 48 & 202 & 176 & 3.1 & 1.1 & $S-S ; g^{+}, t ; g^{+} ;{ }_{3}^{2} T$ \\
\hline-13 & 62 & 182 & 256 & 202 & 196 & 57 & 9 & 180 & 3.8 & 1.8 & $A-A ; g^{-}, t ; g^{+} ;{ }_{3}^{2} T$ \\
\hline 16 & 58 & 183 & 235 & 83 & 186 & 186 & -25 & 193 & 5.1 & 3.1 & $A-A ; t, g^{+} ; t ;{ }_{3} E$ \\
\hline 31 & 56 & 184 & 274 & 143 & 184 & 178 & 56 & 181 & 6.4 & 4.5 & $A-A ; g^{-}, t ; t ;{ }_{3}^{2} T$ \\
\hline 41 & 60 & 188 & 274 & 294 & 181 & 50 & 85 & 166 & 6.8 & 4.8 & $\begin{array}{l}A-A ; g^{-}, g^{-} ; g^{+} ;{ }^{2} E \\
\text { (B) }\end{array}$ \\
\hline
\end{tabular}

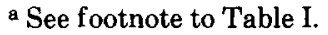
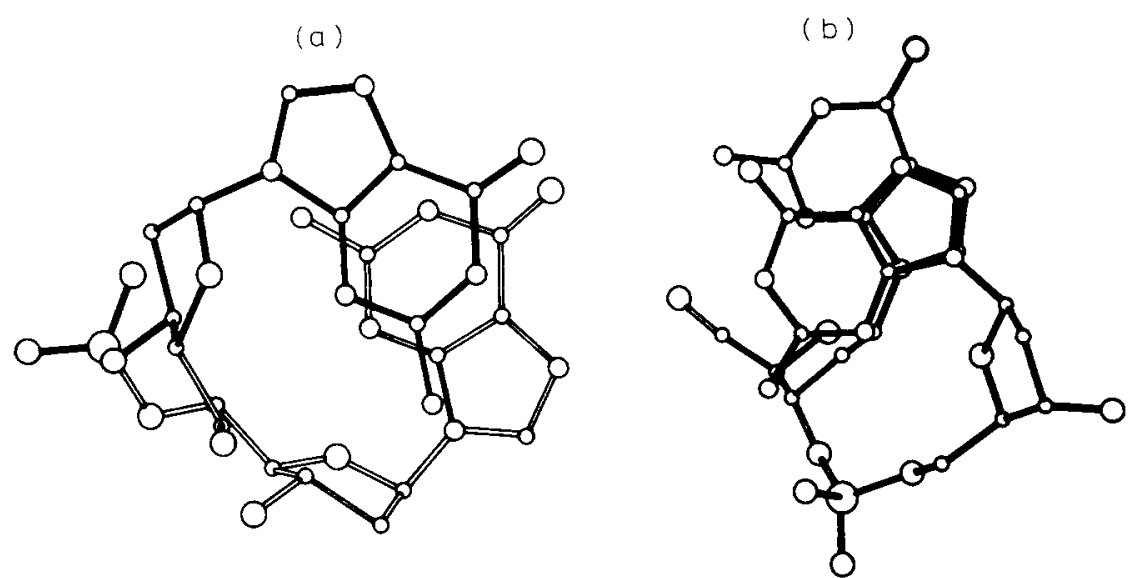

Fig. 4. (a) Global minimum energy conformation of dGpdG, $\Delta E_{1}=0$. Dihedral angles given in Table IV. (b) $\mathrm{C}\left(2^{\prime}\right)$-endo region lowest-energy conformation of dGpdG, $\Delta E_{2}=0$. Dihedral angles given in Table IV. 
TABLE V

Selected Minimum Energy Conformations of $\mathrm{dTpdT}^{\mathrm{a}}$

\begin{tabular}{|c|c|c|c|c|c|c|c|c|c|c|c|}
\hline$\chi^{\prime}$ & $\psi^{\prime}$ & $\varphi^{\prime}$ & $\omega^{\prime}$ & $\omega$ & $\varphi$ & $\psi$ & $\underline{x}$ & $\mathbf{P}$ & $\Delta E_{1}$ & $\Delta E_{2}$ & $\begin{array}{c}\text { Description } \\
\sim \omega^{\prime}, \omega ; \psi ; \\
\text { Pucker }\end{array}$ \\
\hline \multicolumn{12}{|c|}{$\mathrm{C}\left(3^{\prime}\right)$-endo Region } \\
\hline 10 & 63 & 201 & 316 & 278 & 183 & 51 & 24 & 19 & 0 & & $\begin{array}{l}g^{-}, g^{-} ; g^{+} ;{ }^{3} E \\
\text { (A) }\end{array}$ \\
\hline 44 & 62 & 192 & 302 & 283 & 177 & 55 & 43 & 13 & 0.1 & & $\begin{array}{l}g^{-}, g^{-} ; g^{+} ;{ }^{3} E \\
\text { (A) }\end{array}$ \\
\hline 17 & 53 & 171 & 23 & 80 & 194 & 70 & 14 & 12 & 0.3 & & $g^{+}, g^{+*} ; g^{+} ;{ }_{2}^{3} T$ \\
\hline 44 & 179 & 175 & 42 & 235 & 166 & 307 & 6 & 0 & 1.5 & & $g^{+}, t^{*} ; g^{-} ;{ }_{2}^{3} T$ \\
\hline 38 & 178 & 188 & 290 & 166 & 207 & 145 & 21 & 0 & 2.7 & & $g^{-}, t ; t ;{ }_{2}^{3} T$ \\
\hline \multicolumn{12}{|c|}{$\mathrm{C}\left(2^{\prime}\right)$-endo Region } \\
\hline 66 & 177 & 171 & 267 & 148 & 192 & 179 & 63 & 186 & 3.1 & 0 & $g^{-}, t ; t ;{ }_{3}^{2} T$ \\
\hline 69 & 289 & 192 & 63 & 168 & 179 & 55 & 12 & 192 & 3.6 & 0.5 & $g^{+}, t ; g^{+} ;{ }_{3}^{2} T$ \\
\hline 143 & 63 & 180 & 266 & 195 & 170 & 62 & 19 & 189 & 4.6 & 1.5 & $g^{-}, t ; g^{+} ;{ }_{3}^{2} T$ \\
\hline 41 & 53 & 193 & 279 & 300 & 171 & 59 & 75 & 173 & 5.7 & 2.6 & $\begin{array}{l}g^{-}, g^{-} ; g^{+} ;{ }_{3}^{2} T \\
\text { (B) }\end{array}$ \\
\hline 20 & 57 & 285 & 185 & 306 & 165 & 56 & 28 & 185 & 9.2 & 6.1 & $t, g^{-} ; g^{+} ;{ }_{3}^{2} T$ \\
\hline
\end{tabular}

a See footnote to Table I.

$\mathrm{kcal} / \mathrm{mol}$ higher in energy than the A-form. This is probably due to a steric effect of the methyl hydrogens, which prevents the bases from approaching closely enough for stacking interaction. ${ }^{23}$ The $\omega^{\prime}, \omega$ region found in the crystal of pdTpdT, $t, g^{-}$, is not low energy. The exact crystal angles ${ }^{36}$ $\left(\chi^{\prime}=27^{\circ}, \psi^{\prime}=46^{\circ}, \phi^{\prime}=252^{\circ}, \omega^{\prime}=163^{\circ}, \omega=288^{\circ}, \phi=187^{\circ}, \psi=41, \chi=24^{\circ}\right.$, $\mathrm{P}$ taken as $180^{\circ}$ ) had an energy $\Delta E_{2}=10.8 \mathrm{kcal} / \mathrm{mol}$. After minimizing, the $t, g^{-}$conformation shown last in the table was obtained, with $\Delta E_{2}=$ $6.1 \mathrm{kcal} / \mathrm{mol}$.

\section{Energy Contour Maps}

Some results for $\mathrm{dApdA}$ serve as examples of our findings.

Figure 5(a) shows a map of $\mathrm{dApdA}$ in the $\omega^{\prime}, \omega$ plane with $\mathrm{C}\left(3^{\prime}\right)$-endo pucker and $\psi=g^{+}$. The other dihedral angles were fixed near those of the $g^{-}, g^{-}$minimum (Table II). The three low-energy regions $g^{-}, g^{-} ; g^{-}, t$; and $g^{+}, g^{+}$are evident. The $g^{+}, g^{+}$and the $g^{-}, t$ conformations are linked by a contour at $\sim 7 \mathrm{kcal} / \mathrm{mol}$ and a $14 \mathrm{kcal} / \mathrm{mol}$ path exists between the $g^{+}, g^{+}-g^{-}, t$ and the $g^{-}, g^{-}$A-form domain. The overall appearance of this map is similar to that of ApA and other ribodinucleoside phospates. ${ }^{17}$

Two $\omega^{\prime}, \omega$ maps were constructed with $\mathrm{C}\left(2^{\prime}\right)$-endo pucker, one with $\psi=$ $g^{+}$and the other with $\psi=$ trans. Results for $\psi=g^{+}$are shown in Fig. 5(b). In this map the other angles were fixed near the B-form minimum. Only the $g^{-}, g^{-}$region appears low energy in the map because the $g^{+}, t$ low-energy conformation (Table II) has $\chi^{\prime}$ and the sugar pucker very different from that of the B-form. The general vicinity of the $g^{+}, t$ minimum appears 


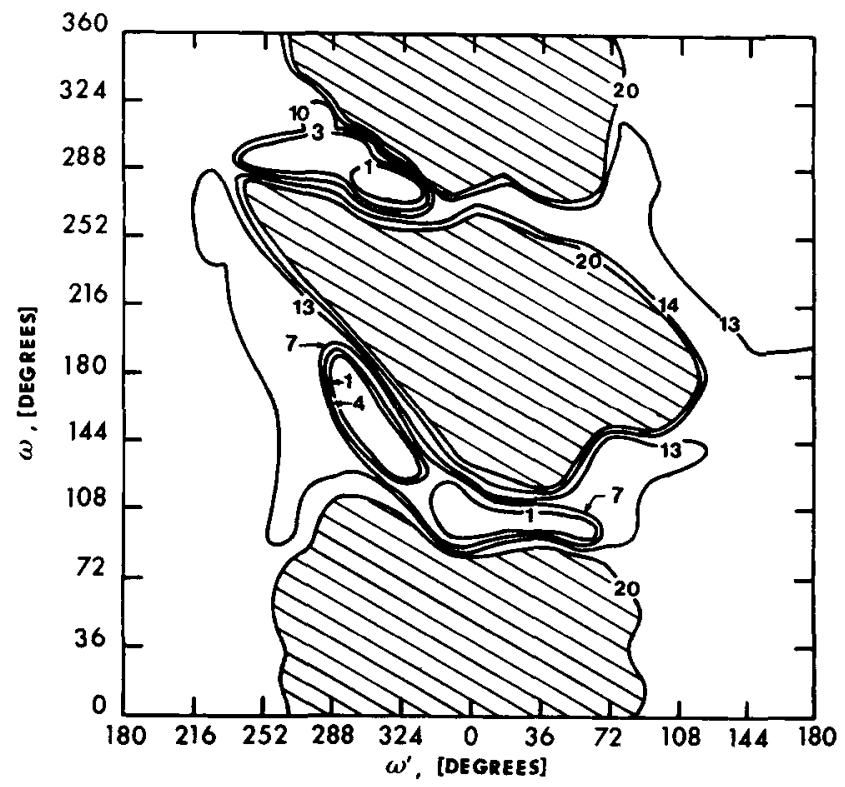

(a)

Fig. 5. (a) Energy contour map in the $\omega^{\prime}, \omega$ plane for dApdA with $\mathrm{C}\left(3^{\prime}\right)$-endo pucker. Other angles fixed at $\chi^{\prime}=5^{\circ}, \psi^{\prime}=60^{\circ}, \phi^{\prime}=210^{\circ}, \phi=185^{\circ}, \psi=50^{\circ}, \chi=20^{\circ}, \mathbf{P}=7^{\circ}$. Shaded areas are above $20 \mathrm{kcal} / \mathrm{mol}$. Energies are $\Delta E_{1}$ (see footnote to Table I). (b) Energy contour map in the $\omega^{\prime}, \omega$ plane for dApdA with $\mathrm{C}\left(2^{\prime}\right)$-endo pucker. Other angles fixed at $\chi^{\prime}=75^{\circ}, \psi^{\prime}=60^{\circ}$, $\phi^{\prime}=170^{\circ}, \phi=180^{\circ}, \psi=50^{\circ}, \chi=75^{\circ}, \mathbf{P}=162^{\circ}$. Shaded areas are above $20 \mathrm{kcal} / \mathrm{mol}$. Energies are $\Delta E_{2}$ (see footnote to Table I). (c) Energy contour map in the $\omega^{\prime}, \omega$ plane for dApdA with $\mathrm{C}\left(2^{\prime}\right)$-endo pucker. Other angles fixed at $\chi^{\prime}=50^{\circ}, \psi^{\prime}=60^{\circ}, \phi^{\prime}=180^{\circ}, \phi=190^{\circ}$, $\psi=180^{\circ}, \chi=40^{\circ}, \mathrm{P}=162^{\circ}$. Shaded areas are above $20 \mathrm{kcal} / \mathrm{mol}$. Energies are $\Delta E_{2}$.

within a $14 \mathrm{kcal} / \mathrm{mol}$ contour and no path from the B-form is evident. With $\psi=$ trans, the map shown in Fig. 5(c) was obtained. The other angles were fixed near the $g^{-}, t$ minimum. With these settings, the $g^{-}, t$ region occurred within the $1 \mathrm{kcal} / \mathrm{mol}$ contour and the $t, g^{+}$region was inside a $13 \mathrm{kcal} / \mathrm{mol}$ contour. (A map similar in overall features was obtained when the angles other than $\omega^{\prime}$ and $\omega$ were set near the $t, g^{+}$minimum. However, in this case, the $g^{-}, t$ region was at higher energy.) When the dihedral angles which are fixed in the map calculation are significantly different among the various local minima, the maps do not accurately show the energy relationship between the low-energy regions. Minimized maps are needed to overcome this problem of interdependence caused by the fixed parameters, but the cost is prohibitive.

\section{Effect of Variations in Parameters}

An evaluation was made of the influence of a change in dielectric constant [Eq. (3)] on the depth and position of the local minima. For this purpose, dApdA was chosen as a representative molecule. Local minima shown in 


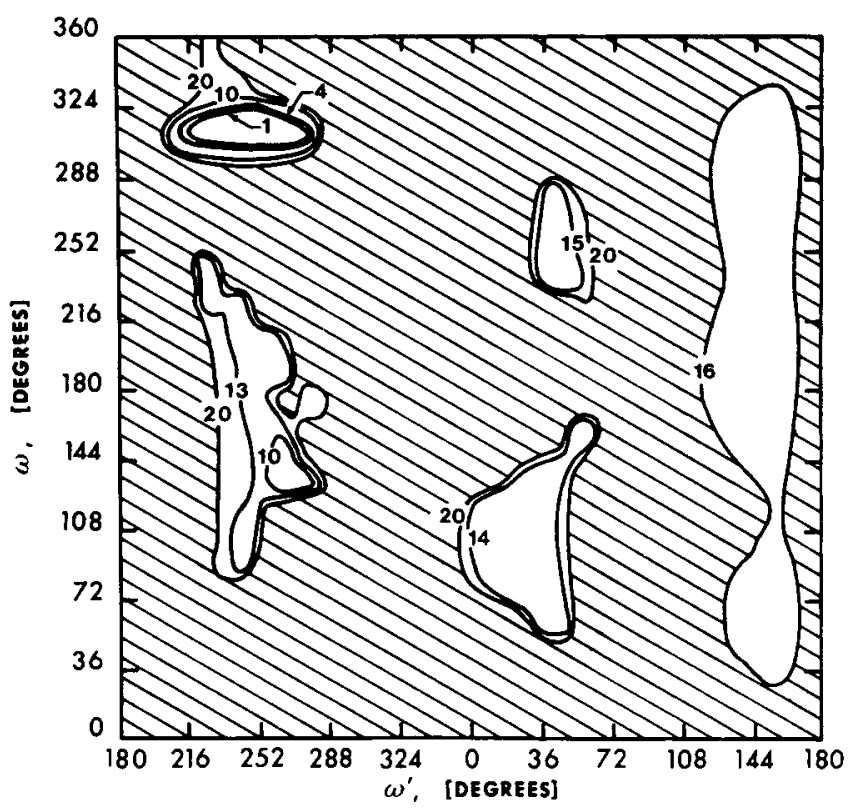

(b)

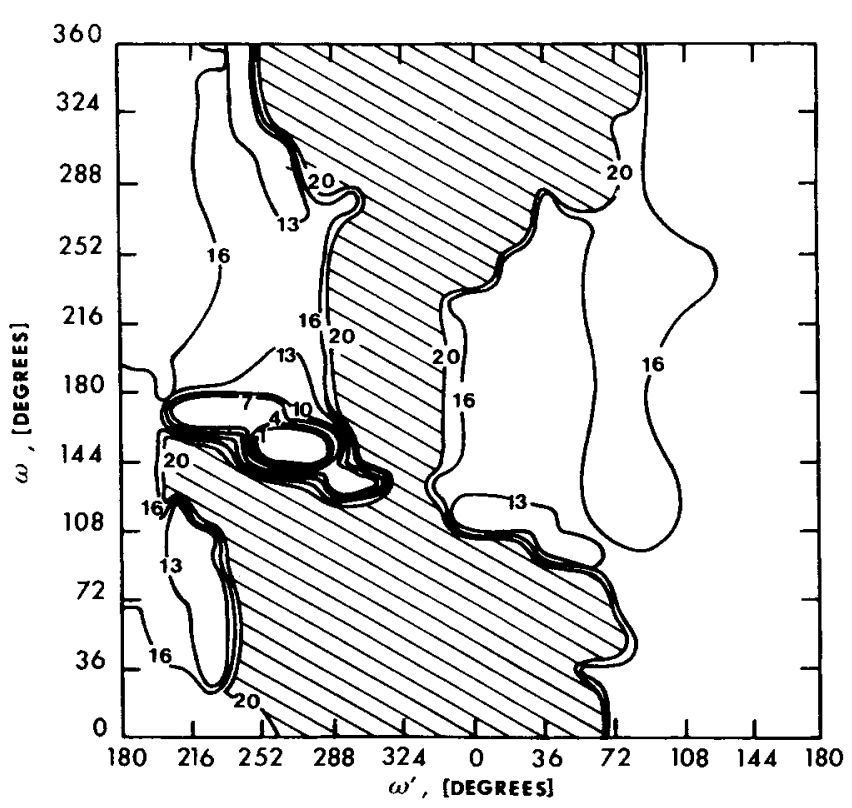

(c)

Fig. 5 (continued from previous page)

Table I (obtained with $\epsilon=4$ ) served as starting conformations. Dielectric constants, $\epsilon$, of $2,3,10,20,30$, and 70 were employed. Changing the dielectric constant has a systematic effect on the relative energy of each 
conformation, but almost no effect on the actual dihedral angles. Results for the most important conformers are shown in Fig. 6. Relative energies varied by about $2 \mathrm{kcal} / \mathrm{mol}$, largely in the range of $2\langle\epsilon\rangle 10$. We see from this figure that the A-form is preferred over the $g^{-}, t$ conformation at a dielectric constant above 10. The B-form also becomes more favorable with increasing $\epsilon$. Increasing $\epsilon$ partly simulates the effect of water and/or salt, but it does not account for specific coulombic interactions of these moieties.

The effect of a change in the parameters $a$ and $b$ in the Lennard-Jones potential of Eq. (2) was also investigated. The low-energy conformations of all the molecules were used as starting parameters in a minimization in which the $a$ 's and $b$ 's were changed, so that two atoms could not approach each other more closely than the sum of their van der Waals radii $+0.2 \AA$. This is a practice frequently employed in potential energy calculations to prevent favorable coulombic interactions from causing a violation of the van der Waals contact distance. With the changed parameters the minima obtained were generally within $\sim 2 \mathrm{kcal} / \mathrm{mol}$ of those found with the original parameters; the dihedral angles remained in the same regions, within $\sim 30^{\circ}$. In most cases, the differences were much smaller. In a few instances, low-energy conformations were calculated with the original parameters which had close contacts involving the free $\mathrm{O}^{\prime}$. (Usually in the $g^{-}$region of $\psi$.) When the parameters were changed, these conformations had considerably higher energy, and were not included in Tables I-V. Otherwise,

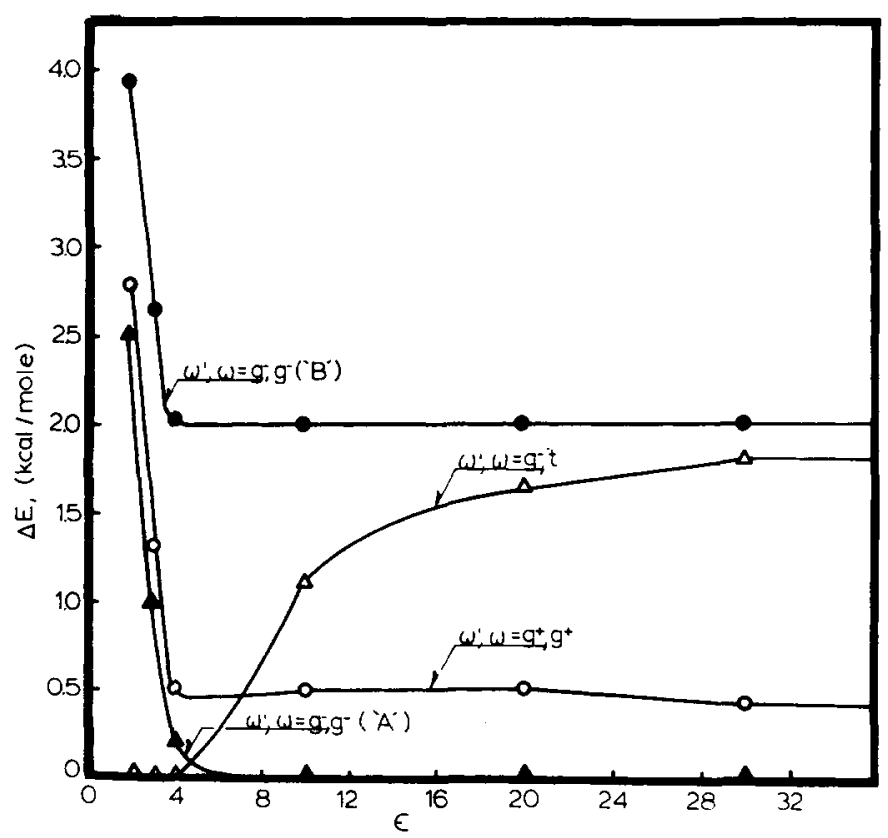

Fig. 6. Relative energies of $\mathrm{dApdA}$ conformers as a function of dielectric constant. Energies are $\Delta E_{1}$. 
the altered parameters produced, if anything, less satisfactory conformations (for example, the $g^{+}, g^{+}$conformation of $\omega^{\prime}, \omega$ was more eclipsed).

\section{Summary of Low-Energy Conformations}

Table VI summarizes the low-energy conformational regions (up to $\sim 5$ $\mathrm{kcal} / \mathrm{mol}$ for each sugar pucker) obtained for all the molecules examined, including higher-energy forms not listed in earlier tables. This table shows that there are only a limited number of low-energy conformations. With $\mathrm{C}\left(3^{\prime}\right)$-endo pucker, the $g^{+}$domain of $\psi$ contains the preponderance of the low-energy forms. These are: $\omega^{\prime}, \omega=g^{-}, g^{-} ; g^{+} g^{+}$; and $g^{-}, t$. With $\psi=$ trans, the energies are higher. The $t, g^{+}$and the $g^{-}, t$ (Watson-Crick conformation) regions of $\omega^{\prime}, \omega$ are favorable. With $\psi=g^{-}$, skewed con-

TABLE VI

Summary of Low-Energy $\omega^{\prime}, \omega$ Regions ${ }^{\mathrm{a}}$

\begin{tabular}{|c|c|c|c|c|}
\hline dApdA & $\mathrm{dTpdT}$ & $\mathrm{dGpdG}$ & $\mathrm{dCpdC}$ & $\mathrm{dGpdC}$ \\
\hline \multicolumn{5}{|c|}{$\mathrm{C}\left(3^{\prime}\right)$-endo-C $\left(2^{\prime}\right)$-exo Region } \\
\hline \multicolumn{5}{|c|}{$\psi \sim 60^{\circ}$} \\
\hline$g^{-}, t(0)$ & $g^{-} g^{-}(0)$ & $g^{-}, t(1.5) S-S$ & $g^{+}, g^{+}(0)$ & $g^{-}, g^{-}(0)$. \\
\hline$g^{-}, g^{-}(0.2)$ & $g^{+} g^{+}(0.3)$ & $g^{+}, g^{+*}(3.6) S-S$ & $g^{-}, g^{-}(2.2)$ & $g^{+}, g^{+*}(1.3)$ \\
\hline$g^{+}, g^{+}(0.5)$ & $g^{-}, t(4.2)$ & $g^{-}, t(5.1)$ & $g^{+}, g^{+*}(4.1)$ & \\
\hline$g^{+}, t^{*}(3.1)$ & $g^{+} g^{-}(4.7)$ & $g^{-}, g^{-}(6.7)$ & & \\
\hline & & $\psi \sim 180^{\circ}$ & & \\
\hline$t, g^{+}(1.7)$ & $g^{-}, t(2.7)$ & $g^{-}, t(2.7) A-S$ & & $g^{-}, t(2.4)$ \\
\hline$g^{-}, t(2.7)$ & & & & \\
\hline$g^{+}, g^{+}(3.4)$ & & & & \\
\hline & & $\psi \sim 300^{\circ}$ & & \\
\hline$g^{+}, t^{*}(1.6)$ & $g^{+}, t^{*}(1.5)$ & $g^{+}, t^{*}(0) S-S$ & $g^{+}, t^{*}(2.3)$ & $g^{+}, t^{*}(4.5)$ \\
\hline$g^{-}, g^{-}(4.6)$ & $g^{+}, g^{-}(4.0)$ & & $g^{-}, g^{-}(4.1)$ & \\
\hline$g^{-}, g^{+}(4.6)$ & & & & \\
\hline \multicolumn{5}{|c|}{$\mathrm{C}\left(2^{\prime}\right)$-endo-C $\left(3^{\prime}\right)$-exo Region } \\
\hline \multicolumn{5}{|c|}{$\psi \sim 60^{\circ}$} \\
\hline$g^{-} g^{-}(0)$. & $g^{+}, t(0.5)$ & $g^{+}, t(1.1) S-S$ & $g^{+}, t(0)$ & $g^{-}, g^{-}(0)$ \\
\hline$g^{+}, t(0.7)$ & $g^{-}, t(1.5)$ & $g^{-}, t(1.8)$ & $g^{-}, g^{-}(2.3)$ & $g^{+}, t(4.2)$ \\
\hline$g^{-}, t(2.3)$ & $g^{-}, g^{-}(2.7)$ & $g^{-}, g^{-}(4.8)$ & $g^{-}, t(3.2)$ & \\
\hline & & & $t, g^{-}(4.6)$ & \\
\hline \multicolumn{5}{|c|}{$\psi \sim 180^{\circ}$} \\
\hline$t, g^{+*}(0.4)$ & $g^{-}, t(0)$ & $g^{-}, t(0) S-S$ & $g^{-}, t(2.2)$ & $g^{-}, t(0.6)$ \\
\hline$g^{-}, t(0.8)$ & & $t, g^{+*}(3.1)$ & $t, g^{+*}(2.8)$ & \\
\hline & & $g^{-}, t(4.5)$ & & \\
\hline \multicolumn{5}{|c|}{$\psi \sim 300^{\circ}$} \\
\hline$g^{-}, g^{-}(1.3)$ & $t, g^{+*}(3.7)$ & $g^{+}, g^{-}(0.9) S-S$ & $g^{-}, g^{-}(4.1)$ & $t, g^{+*}(2.5)$ \\
\hline$t, g^{+*}(3.3)$ & & $g^{-}, g^{-}(3.7) A-S$ & & \\
\hline
\end{tabular}

a $*$ = skewed; bases $3^{\prime}$-anti-5'-anti $(A-A)$ unless designated syn $(S)$. Numbers in parentheses are energies in $\mathrm{kcal} / \mathrm{mol}$. In the $\mathrm{C}\left(3^{\prime}\right)$-endo region these are $\Delta E_{1}$, the energy difference between the given conformation and the $\mathrm{C}\left(3^{\prime}\right)$-endo lowest-energy form. In the $\mathrm{C}\left(2^{\prime}\right)$-endo region, they are $\Delta E_{2}$, the energy difference between the given conformation and the $\mathrm{C}\left(2^{\prime}\right)$-endo lowest-energy form (Tables I-V). 
formations in the $g^{+}, t-g^{+}, g^{-}$vicinity are low energy. In the $\mathrm{C}\left(2^{\prime}\right)$-endopuckering region with the $g^{+}$domain of $\psi$, the $g^{-}, g^{-}$and $g^{+}, t$ regions of $\omega^{\prime}, \omega$ predominate. The $g^{-}, t$ conformation is also low energy. With $\psi=$ trans, the $g^{-}, t$ (Watson-Crick) region is most important, and the skewed $t, g^{+}$conformation is also favorable. With $\psi=g^{-}$, energies are generally higher than for the other two regions of $\psi ; \omega^{\prime}, \omega=g^{-}, g^{-}$and skewed $t, g^{+}$ are found recurringly. In terms of lowest energy and widest accessibility to the different molecules, the most important conformations are: $\mathrm{C}\left(3^{\prime}\right)$ endo-puckering regions: $\psi=g^{+} ; \omega^{\prime}, \omega=g^{-}, g^{-} ; g^{+}, g^{+} ;$and $g^{-}, t ; \mathrm{C}\left(2^{\prime}\right)$ endo-puckering region: $\psi=g^{+}, \omega^{\prime}, \omega=g^{-}, g^{-} ;$and $g^{+}, t ; \psi=t ; \omega^{\prime}, \omega=g^{-}, t$ and $t, g^{+}$(skewed). dGpdC has the fewest low-energy conformations other than the A- and B-form helices, and appears therefore to be most prone to exist in these helical conformations. The A-form is at or very near the lowest energy in the $\mathrm{C}\left(3^{\prime}\right)$-endo-puckering domain for $\mathrm{dGpdC}$, dApdA, and $\mathrm{dTpdT}$. The $\mathrm{B}$-form is lowest energy in the $\mathrm{C}\left(2^{\prime}\right)$-endo region for $\mathrm{dGpdC}$ and dApdA. Only dGpdG has A- and B-forms that are rather high in energy, as a consequence of its calculated preference for syn bases.

\section{DISCUSSION}

\section{The Restricting Effect of the Bases on Conformation}

It is worthwhile to compare our results with those of Yathindra and Sundaralingam, ${ }^{37}$ who made conformational calculations for the backbone (no bases) of deoxydinucleoside monophosphates and triphosphates. In this way we may be able to infer what additional conformational restrictions are imposed by the bases. For the monophosphates with ${ }^{3} E$ pucker and $\psi=g^{+}$, they obtain a global minimum with $\omega^{\prime}, \omega=g^{+}, t$. Additional conformations within $1 \mathrm{kcal} / \mathrm{mol}$ have $\omega^{\prime}, \omega=g^{-}, t ; g^{-}, g^{-} ; g^{+}, g^{+} ;$and $g^{+}, g^{-}$ (skewed). With the triphosphate, only the $g^{-}, g^{-}$and the $g^{-}, t$ regions are of lowest energy. We find $\omega^{\prime}, \omega=g^{-}, g^{-} ; g^{+}, g^{+}$; and $g^{-}, t$ to be low energy (Table VI). Thus, at the monophosphate level, the bases produce restrictions like those caused by the two added phosphates except that the $\mathrm{g}^{+}, \mathrm{g}^{+}$conformer is not eliminated by the bases, but is disfavored by the extra phosphates. In the $\mathrm{C}\left(2^{\prime}\right)$-endo-puckering domain, Yathindra and Sundaralingam find the $g^{-}, g^{-}$B-form helix the global minimum for the triphosphate, and the $g^{+}, t$ conformation is also in the lowest-energy region. The $g^{-}, t$ and the $g^{+}, g^{+}$conformers are low energy only with monophosphates. We do not find the $g^{+}, g^{+}$conformer to be low energy in the monophosphates, which is again a consequence of the restricting effect of the bases.

\section{Conformational Flexibility in $\psi$, Sugar Pucker, and $\omega^{\prime}, \omega$ in DNAs and RNAs}

Our calculations show that conformational flexibility in $\psi$ is important 
for the DNA dimeric subunits, particularly with $\mathrm{C}\left(2^{\prime}\right)$-endo pucker, where the $\psi=$ trans region is favored (see Table VI). There are indications that variability in $\psi$ may be greater in deoxy than in ribonucleotides. $\mathrm{Nmr}$ studies of ribo- and deoxynucleotides have suggested this possibility. ${ }^{38}$ Furthermore, in the crystal of the deoxy fragment $5^{\prime} \mathrm{dGmp},{ }^{39,40} \psi$ is trans, while crystalline $5^{\prime} \mathrm{Gmp}^{41}$ has $\psi=g^{+}$. The nucleotide $5^{\prime} \mathrm{dUmp}^{42}$ has $\psi=$ $g^{-}$in the crystal, while $5^{\prime} \mathrm{Ump}^{43}$ has $\psi=g^{+}$. However, in crystalline tRNA, ${ }^{5-8}$ the trans and to a lesser extent the $g^{-}$regions are observed, although the $g^{+}$domain predominates. The preference for the trans and $g$ - domains of $\psi$ could be sequence dependent. We find that the lowestenergy conformations with $\mathrm{C}\left(2^{\prime}\right)$-endo-type pucker have $\psi=$ trans in dGpdG and dTpdT, but $\psi$ is $g^{+}$for the other molecules at the $\mathrm{C}\left(2^{\prime}\right)$-endo lowest-energy minimum.

Our results also show that the DNA subunits are permitted flexibility in the sugar pucker, in that both the $\mathrm{C}\left(3^{\prime}\right)$-endo and the $\mathrm{C}\left(2^{\prime}\right)$-endo regions are low energy. For dGpdC the B-form is only $0.2 \mathrm{kcal} / \mathrm{mol}$ above the global minimum. The RNAs are less flexible in this conformational aspect, especially in their $\omega^{\prime}, \omega=g^{-}, g^{-}$conformers. While the A-form calculated conformations of deoxydinucleoside phosphates are very similar to the A-forms calculated for the analogous ribo molecules ${ }^{17}$ (which is consistent with the existence of A-form DNA-RNA hybrids ${ }^{44,45}$ ), B-forms are energetically disfavored in the ribodinucleoside phosphates. The B-forms are either not calculated as a local minimum or they are more than $6 \mathrm{kcal} / \mathrm{mol}$ higher in energy than the A-forms, ${ }^{17}$ even for GpC. This is due to steric hindrance between the $5^{\prime}$ base and the $2^{\prime} \mathrm{OH}$ of the $3^{\prime}$ ribose. ${ }^{17}$ Some ribo sequences do have calculated minimum energy conformations with ${ }^{2} E$ pucker at energies of 1-2 kcal/mol. These have $\omega^{\prime}, \omega$ conformations other than $g^{-}, g^{-}$. For example, ApA has a conformer at $1.8 \mathrm{kcal} / \mathrm{mol}$ with $\omega^{\prime}, \omega=g^{-}, t, \psi=g^{+},{ }^{2} E .{ }^{17}$ In crystalline tRNA ${ }^{5-8}$ the sugar pucker is overwhelmingly $\mathrm{C}\left(3^{\prime}\right)$-endo.

Conformational flexibility in the $\omega^{\prime}, \omega$ angle pair is apparent in our calculated results for the deoxydinucleoside phosphates. In this respect the ribo subunits are similar. With $\psi=g^{+}$, and ${ }^{3} E$ pucker, the DNA and RNA subunits ${ }^{17}$ have the same three calculated low-energy $\omega^{\prime}, \omega$ regions: $g^{-}, g^{-}$; $g^{+}, g^{+}$, and $g^{-}, t$. However, the $g^{+}, g^{+}$and $g^{-}, t$ conformers are less prone to be skewed in the deoxy molecules. It is interesting to note that in crystalline tRNA ${ }^{5-8}$ the hairpin turn in the anticodon loop and the T $\psi \mathrm{C}$ loop have $\omega^{\prime}, \omega=g^{-}, t, \psi=g^{+}$, which we calculated as the global minimum for UpU. ${ }^{17}$ These loops have $\mathrm{U}$ or $\psi$ bases at the turn.

\section{Comparison of Calculations with Experiments}

Crystal structure of $p d T p d T$. Of the sequences examined by us, the only relevant crystal structure at the dinucleotide level is that of pdTpdT, ${ }^{36}$ which, however, has an additional $5^{\prime}$ phosphate. The molecule has sugar pucker $\mathrm{C}\left(2^{\prime}\right)$-endo, bases anti, $\omega^{\prime}, \omega=t, g^{-}$. This is a conformational region 
which we find at $6.1 \mathrm{kcal} / \mathrm{mol}$ above the $\mathrm{C}\left(2^{\prime}\right)$-endo lowest-energy form. The same $\omega^{\prime}, \omega$ conformation was obtained for one of the conformers in crystalline UpA; $; 6,47$ it was also not among the calculated lowest-energy mini$\mathrm{ma},{ }^{18}$ although the other UpA conformer, with $\omega^{\prime}, \omega=g^{+}, g^{+}$, is low energy. Govil ${ }^{48}$ also finds the $t, g^{-}$minimum to be of significantly higher energy compared to $g^{-}, g^{-}$in his calculations on diribose triphosphate. In crystalline UpA and pdTpdT there are extensive intermolecular hydrogen bonds, which yield sufficient energy to permit the molecule to adopt conformations which are of higher energy in their absence. On the other hand, solution studies of UpA have shown that the predicted $\omega^{\prime}, \omega=g^{-}, g^{-}$global minimum is, in fact, the predominant conformer there. ${ }^{49}$ Possibly, a similar situation may occur for pdTpdT in solution.

$d A p d A$ in solution. In solution, high-resolution $\mathrm{nmr}$ is the technique most capable of yielding detailed conformational information. Sarma and coworkers ${ }^{50,51}$ found $\mathrm{dApdA}$ to have the following predominant conformational features: sugar pucker $\mathrm{C}\left(2^{\prime}\right)$-endo, $\phi^{\prime}=$ trans and $g^{-}, \phi=$ trans, $\psi$ and $\psi^{\prime}$ (the exocyclic $\mathrm{C} 4^{\prime}-\mathrm{C} 5^{\prime}$ torsion) $=\mathrm{g}^{+}$. The bases are presumed anti. Comparing these results with our $\mathrm{C}\left(2^{\prime}\right)$-endo conformations listed in Table II, we find that they are entirely compatible only with the B-form lowest-energy conformation, which agrees with the most recent findings of Cheng and Sarma.52 There are, however, sizable fractions of other conformers present in solution. For example, $\psi$ has $13 \%$ conformers other than $g^{+} .52$ We suggest that likely candidates for the other conformations in solution have $\omega^{\prime}, \omega=t, g^{+} ; \psi=t ; \omega^{\prime}, \omega=g^{+}, t ; \psi=g^{+} ;$and $\omega^{\prime}, \omega=g^{-}, t ; \psi$ $=t$. All these conformers are stacked in the deoxydinucleoside phosphate except $\omega^{\prime}, \omega=g^{+}, t ; \psi=g^{+}$. The $\mathrm{C}\left(3^{\prime}\right)$-endo-puckering domain is populated to the extent of $22 \%$ and $37 \%$ for the $3^{\prime}$ and $5^{\prime}$ sugars, respectively, in solu-

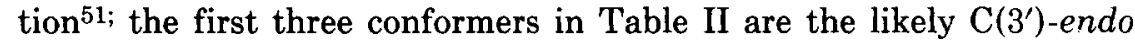
forms.

$d T p d T$ in solution. Wood et al..$^{53}$ obtained generally similar conformational preferences for $\mathrm{dTpdT}$ as were found for dApdA. With the preference for the $g^{+}$domain of $\psi$, our second lowest-energy conformation of dTpdT in the $\mathrm{C}\left(2^{\prime}\right)$-endo region $\left[\Delta E_{2}=0.5 \mathrm{kcal} / \mathrm{mol}\right.$ (Table V)] would be a plausible choice for the predominant conformation. This has $\omega^{\prime}, \omega=$ $g^{+}, t$, and is also consistent with the belief of Wood et al. ${ }^{53}$ that there is little stacking in dTpdT. However, there is little base-base interaction in the calculated B-form of dTpdT, ${ }^{23}$ and this conformer could also contribute to the conformational mix in solution. The recent $\mathrm{nmr}$ results of Cheng and Sarma ${ }^{52}$ are interpreted as consistent with $\omega^{\prime}, \omega=t, g^{-}$, as in the pd'TpdT crystal.

$d G p d C$ in solution. Young and $\mathrm{Krugh}^{54}$ studied a number of deoxydinucleoside monophosphates and deoxydinucleotides, some of which were potentially self-complementary or constituted potentially complementary mixtures, and others which were noncomplementary. Their results are consistent with the interpretation that $\mathrm{dGpdC}$ in solution forms a miniature Watson-Crick base-paired double helix, which agrees with our calculated A- or B-form helical lowest-energy conformations for this molecule. 
Sugar pucker. In solution the DNAs prefer $\mathrm{C}\left(2^{\prime}\right)$-endo-type pucker, while we calculate lower absolute energies for the isolated $\mathrm{C}\left(3^{\prime}\right)$-endo forms. However, even in solution the ${ }^{3} E$ conformer is important for deoxydinucleoside phosphates, contributing $\sim 20-50 \%$ to the conformational blend, ${ }^{52}$ depending on base sequence. Quantum mechanical calculations on the nucleoside deoxyuridine show two global minima, one in each puckering domain, but for deoxyadenosine $\mathrm{C}\left(2^{\prime}\right)$-endo is preferred by $\sim 1 \mathrm{kcal} / \mathrm{mol} .{ }^{30}$ The present calculated energy differences between the A- and B-forms are sequence dependent and sometimes very small, but they always favor the A-form. Kister and Dashevsky ${ }^{22}$ obtained similar results in their calculations on a dApdT duplex, as did Calascibetta et al. ${ }^{55}$ for both duplex poly (dA-dT) and poly(dG-dC). Classical calculations which do not include the bases, on the other hand, show an energetic preference for the B-form. ${ }^{37}$ It is possible that a specific interaction of the bases with water and/or salt enhances the stability of the $\mathrm{C}\left(2^{\prime}\right)$-endo pucker. In fibers of calf-thymus DNA $^{56,57}$ the A-form [C $\left(3^{\prime}\right)$-endo] is generally favored under low humidity and at low salt concentrations.

The puckering preference in duplex fibers is sequence dependent. This preference may correlate with our calculated energy differences for the Aand B-forms. While the present calculations are for deoxydinucleoside monophosphate single-stranded structures, the calculated conformational angles of the A- and B-forms are very similar to those obtained in duplex fibers, ${ }^{57,58}$ although the differences translate into more prominent differences in helix geometry. ${ }^{23}$ However, only small adjustments, with low energetic cost are needed to permit duplex formation, ${ }^{23}$ indicating that the terminal phosphates are not very important in the $\mathrm{A}$ - and $\mathrm{B}$-form helical conformers. Fibers of poly $(\mathrm{dG}-\mathrm{dC}) \cdot$ poly $(\mathrm{dG}-\mathrm{dC})$ and poly $(\mathrm{dA}-\mathrm{d} T) \cdot \mathrm{pol}-$ $\mathrm{y}(\mathrm{dA}-\mathrm{dT})$ exist under low salt conditions that normally yield the A-form, in a variant of the B-form, which has been termed D-DNA. ${ }^{59}$ These can also occur in the normal B-form, and the A-form is metastable. We calculate an energetic preference of only $0.2 \mathrm{kcal} / \mathrm{mol}$ for the A-form of dGpdC, which can easily be overcome by interactions with water and/or salt, not considered here. Fibers of poly $(\mathrm{dA}) \cdot \operatorname{poly}(\mathrm{d} T)^{60}$ exist in two forms, a double-stranded B-form and a triple-stranded poly $(\mathrm{dT}) \cdot \operatorname{poly}(\mathrm{dA}) \cdot \operatorname{poly}(\mathrm{dT})$ A-form, both at high humidity. We calculate a preference of $1.3 \mathrm{kcal} / \mathrm{mol}$ for the A-form over the B-form in $\mathrm{dApdA}$ and $5.7 \mathrm{kcal} / \mathrm{mol}$ in $\mathrm{dTpdT}$, for the isolated molecules. In the triple strand, the factors of humidity and salt concentration which would otherwise stabilize the B-form may be insufficient to overcome the intrinsic preference of thymine polynucleotides for the A-form. Thus, when two thymine strands are present, the A-helix is observed. $\mathrm{dCpdC}$ has a calculated $5 \mathrm{kcal} / \mathrm{mol}$ preference for the $\mathrm{A}$-form, while the A- and B-forms are calculated almost equal in energy for $\mathrm{dGpdG}$. In fibers of poly $(\mathrm{dG}) \cdot$ poly $(\mathrm{dC})$, the A-form is markedly preferred under any conditions. ${ }^{56}$ Indeed, fibers containing only the B-form do not seem obtainable. Thus, an intrinsic preference for the A-helix by a sequence of thymines or cytidines may compel that conformation to be adopted. A 
further example of this phenomenon is the RNA-DNA hybrids, ${ }^{44,45}$ which are A-form due to the energetic preference of the RNAs. Another point of interest is the observation of Arnott et al. ${ }^{61}$ that the stacking interactions of homopolymer sequences stabilize the A-form. Our calculations are generally consistent with this view.

Guanosines. The conformations of guanosines have attracted some special interest because of their unusual ability to aggregate, producing viscous gels in solution. The calculated preference for syn orientation of the glycosidic bonds has been noted.17,34,35 At the mononucleotide level, there appears to be a syn component in solution, especially in the $3^{\prime}$ nucleotide. ${ }^{62}$ The $\mathrm{nmr}$ work of Davies and Danyluk ${ }^{63}$ admits to a possibly greater preference for the syn rotamer in the $3^{\prime}$ nucleotide over the $5^{\prime}$. The ribodinucleoside phosphates $\mathrm{GpU}$ and $\mathrm{GpA}$ are thought to be predominantly syn in solution, on the basis of $\mathrm{nmr}$ studies. ${ }^{64}$ However, this is not true for $\mathrm{UpG}$ or $\mathrm{ApG}$, nor is it so for $\mathrm{GpC}^{49}$ in solution. Crystalline $5^{\prime}$ dGmp ${ }^{39,40}$ and $5^{\prime} \mathrm{Gmp}^{41}$ have bases anti. Fiber diffraction studies on $5^{\prime} \mathrm{Gmp}$ by Sasisekharan et al. ${ }^{65}$ and by Zimmerman ${ }^{66}$ indicate the bases are anti and form a helical array of tetramers. Thus, experimental results on the orientation of the guanosine bases are mixed. Sasisekharan et al. ${ }^{65}$ attribute the in vacuo calculated syn conformational preference in $5^{\prime} \mathrm{Gmp}$ to the electrostatic interaction between the 2 amino group and the phosphate oxygens. They point out that this can also be satisfied by intermolecular interactions when possible, and that the propensity for guanosines to aggregate and their tendency to have a syn glycosidic torsion probably has the same origin.

\section{CONCLUSION}

The deoxydinucleoside phosphates studied have a number of low-energy conformations, varying in sugar pucker, $\psi$ and the $\omega^{\prime}, \omega$ angle pair. The most important conformers in the $\mathrm{C}\left(3^{\prime}\right)$-endo-puckering region are: $\psi=g^{+}$; $\omega^{\prime}, \omega=g^{-}, g^{-} ; g^{+}, g^{+} ;$and $g^{-}, t$. With $\mathrm{C}\left(2^{\prime}\right)$-endo pucker the most important conformers are: $\psi=g^{+} ; \omega^{\prime}, \omega=g^{-}, g^{-}$and $g^{+}, t ; \psi=t ; \omega^{\prime}, \omega=g^{-}, t$ and $t, g^{+}$ (skewed). These forms include the A- and B-helix and the Watson-Crick helix. The other conformers may occur in the coil form or where DNA kinks. A future publication will examine these minima in relation to their pertinence to coils, kinks, and drug-intercalated DNA.

Grateful acknowledgment is made to the National Institutes of Health for support of this work under Public Health Service Grant GM 22765-01 awarded to S.B. B.H. would like to thank the National Institutes of Health for a postdoctoral fellowship 1 F22 CA02210-01. S.D.S. is supported by National Cancer Institute Grant CA-17613. R.M.W. gratefully acknowledges support from the National Science Foundation (Grant No. PCM77-09726). 


\section{References}

1. Watson, J. D. \& Crick, F. H. C. (1953) Nature 171, 737-738.

2. Langridge, R., Marvin, D. A., Seeds, W. E., Wilson, H. R., Hooper, C. W., Wilkins, M. H. F. \& Hamilton, L. D. (1960) J. Mol. Biol. 2, 38-64.

3. Arnott, S., Chandrasekaran, R. \& Selsing, E. (1975) in Structure and Conformation of Nucleic Acids and Protein-Nucleic Acid Interactions, Sundaralingam, M. \& Rao, S. T., Eds., University Park Press, Baltimore, Md., pp. 577-596.

4. Crick, F. H. C. \& Watson, J. D. (1954) Proc. R. Soc. A 223, 80-96.

5. Jack, A., Ladner, J. \& Klug, A. (1976) J. Mol. Biol. 108, 619-649.

6. Quigley, G., Seeman, N., Wang, A., Suddath, F. \& Rich, A. (1975) Nucleic Acids Res. 2, 2329-2341.

7. Sussman, J. L. \& Kim, S. H. (1976) Biochem. Biophys. Res. Commun. 68, 89-95.

8. Stout, C., Mizuno, H., Rubin, J., Brennam, S., Rao, M. \& Sundaralingam, M. (1976) Nucleic Acids Res. 3, 1111-1123.

9. Olins, D. \& Olins, A. (1974) Science 183, 330-332.

10. Crick, F. H. C. \& Klug, A. (1975) Nature 255, 530-533.

11. Sobell, H. M., Tsai, C., Gilbert, S., Jain, S. \& Sakore, T. (1976) Proc. Natl. Acad. Sci. USA 73, 3068-3072.

12. Olson, W. K. \& Flory, P. J. (1972) Biopolymers 11, 25-56.

13. Lakshminarayanan, A. \& Sasisekharan, V. (1969) Biopolymers 8, 475-488.

14. Lakshminarayanan, A. \& Sasisekharan, V. (1969) Biopolymers 8, 489-503.

15. Yathindra, N. \& Sundaralingam, M. (1973) Biopolymers 12, 297-314.

16. Stellman, S., Hingerty, B., Broyde, S., Subramanian, E., Sato, T. \& Langridge, R. (1973) Biopolymers 12, 2731-2750.

17. Broyde, S., Wartell, R., Stellman, S., Hingerty, B. \& Langridge R. (1975) Biopolymers 14, 1597-1613.

18. Broyde, S., Stellman, S., Hingerty, B. \& Langridge, R. (1974) Biopolymers 13, 12431260 .

19. Stellman, S., Hingerty, B., Broyde, S. \& Langridge, R. (1975) Biopolymers 14, 2049 2060 .

20. Broyde, S., Stellman, S. \& Wartell, R. (1975) Biopolymers 14, 2625-2637.

21. Fujii, S. \& Tomita, K. (1976) Nucleic Acids Res. 3, 1973-1984.

22. Kister, A. \& Dashevsky, V. (1976) Biopolymers 15, 1009-1013.

23. Hingerty, B. \& Broyde, S. (1978) Nucl. Acids Res. 5 (1).

24. Scott, R. A. \& Scheraga, H. A. (1966) J. Chem. Phys. 44, 3054-3069.

25. Arnott, S., Dover, S. \& Wonacott, A. (1969) Acta Crystallogr. B 25, 2192-2206.

26. Renugopalakrishnan, V., Lakshminarayanan, A. \& Sasisekharan, V. (1971) Biopolymers 10, 1159-1167.

27. Sasisekharan, V. (1973) Jerusalem Symp. Quant. Chem. Biochem. 5, 247-260.

28. Altona, C. \& Sundaralingam, M. (1972) J. Am. Chem. Soc. 94, 8205-8212.

29. Snyder, R. G. \& Zerbi, G. (1967) Spectrochim. Acta 23, 391-437.

30. Saran, A., Perahia, D. \& Pullman, B. (1973) Theor. Chim. Acta 30, 31-44.

31. Powell, M. (1964) Computer J. 7, 155-159.

32. Zhurkin, V., Lysov, Y. \& Ivanov, V. (1975) FEBS Lett. 59, 44-47.

33. Brahms, J., Maurizot, J. \& Pilet, J. (1969) Biochim. Biophys. Acta 186, 110-123.

34. Olson, W. K. (1973) Biopolymers 12, 1787-1814.

35. Yathindra, N. \& Sundaralingam, M. (1973) Biopolymers 12, 2075-2082.

36. Camerman, N., Faucett, J. \& Camerman, A. (1973) Science 182, 1142-1143.

37. Yathindra, N. \& Sundaralingam, M. (1975) Biopolymers 14, 2387-2399.

38. Davies, D. D. \& Danyluk, S. S. (1975) Biochemistry 14, 543-554.

39. Young, D., Tollin, P.\& Wilson, H. (1974) Nature 248, 513-514.

40. Viswamitra, M. \& Seshadri, T. (1974) Nature 252, 176-177.

41. Murayama, W., Nagashima, N. \& Shimizu, Y. (1969) Acta Crystallogr. B 25, 22362245 .

42. Viswamitra, M. \& Seshadri, T. (1975) Nature 258, 542-544.

43. Shefter, E. \& Trueblood, K. N. (1965) Acta Crystallogr. 18, 1067-1077. 
44. Milman, G., Chamberlain, M. \& Langridge, R. (1967) Proc. Natl. Acad. Sci. USA 37, 1804-1810.

45. O’Brien, E. \& MacEwan, A. (1970) J. Mol. Biol. 48, 243-261.

46. Sussman, J., Seeman, N., Kim, S. H. \& Berman, H. (1972) J. Mol. Biol. 66, 403-421.

47. Rubin, J., Brennan, T. \& Sundaralingam, M. (1972) Biochemistry 11, 3112-3218.

48. Govil, G. (1976) Biopolymers 15, 2303-2307.

49. Prescott, B., Gamache, R., Livramento, J. \& Thomas, G. J. (1974) Biopolymers 13, 1821-1845.

50. Lee, C., Evans, F. \& Sarma, R. (1975) FEBS Lett. 51, 73-79.

51. Evans, F., Lee, C. \& Sarma, R. (1975) Biochem. Biophys. Res. Commun. 63, 106114.

52. Cheng, D. \& Sarma, R. (1977) J. Am. Chem. Soc. 99, 7333-7348.

53. Wood, D., Hruska, F. \& Ogilvie, K. (1974) Can. J. Chem. 52, 3353-3366.

54. Young, M. \& Krugh, T. (1975) Biochemistry 14, 4841-4847.

55. Calascibetta, F., Dentini, M., DeSantis, P. \& Morsetti, S. (1975) Biopolymers 14, 1667-1684.

56. Arnott, S. \& Selsing, E. (1974) J. Mol. Biol. 88, 551-552.

57. Arnott, S. \& Selsing, E. (1975) J. Mol. Biol. 98, 265-269.

58. Arnott, S. \& Hukins, D. (1972) Biochem. Biophys Res. Commun. 47, 1505-1509.

59. Arnott, S., Chandrasekaran, R., Hukins, D., Smith, P. \& Watts, L. (1974) J. Mol. Biol. $88,523-533$.

60. Arnott, S. \& Selsing, E. (1974) J. Mol. Biol. 88, 509-521.

61. Arnott, S., Hukins, D., Dover, S., Fuller, W. \& Hodgson, A. (1974) J. Mol. Biol. 81, 107-124.

62. Son, T. D. \& Guschlbauer, W. (1975) Nucleic Acids Res. 2, 873-886.

63. Davies, D. D. \& Danyluk, S. S. (1974) Biochemistry 13, 4417-4434.

64. Chachaty, C., Yokono, T., Tran-Dinh, S. \& Guschlbauer, W. (1977) Biophys. Chem. 6, 151-159.

65. Sasisekharan, V., Zimmerman, S. \& Davies, D. R. (1975) J. Mol. Biol. 92, 171-179.

66. Zimmerman, S. (1976) J. Mol. Biol. 106, 663-672.

Received April 5, 1977

Accepted October 28, 1977 